\title{
PERANAN FASILITAS PPI TERHADAP KELANCARAN AKTIVITAS PENDARATAN IKAN DI CITUIS TANGERANG
}

\author{
(ROLE OF FISH LANDING PLACE (PPI) FACILITIES ON FISH LANDING \\ ACTIVTTIES IN CITUIS TANGERANG)
}

Ernani Lubis ${ }^{1}, 2$ dan Nurul Mardiana

Department of Fisheries Resources Utilization, Faculty of Fisheries and Marine Sciences, Bogor Agricultural University (IPB) Bogor, Indonesia, E-mail : ernani_ipb@yahoo.com

\begin{abstract}
Facilities support the role of fishing port activity. Insufficient capacity or unavailability of one of the necessary facilities will be able to hamper the smooth activity of the port. These problems are often found at many fishing ports. PPI Cituis one of the 7 PPI in Tangerang district that contributes the highest region origin income. The purpose of this study to know the condition of capture fisheries in Tangerang Regency, activities and facilities in the PPI Cituis and assess the capacity of the facilities available. The research method is a case to PPI Cituis activities and facilities. Descriptive analysis was performed after the identification of existing activities and the calculation of return on the capacity of the fish auction place, quai and port basin. The results showed that based on thirteen fishing port activities listed in Law No. 45 of 2009 on Fisheries, the PPI Cituis has done it 9. Problem of lack of capacity of the pier $(154.18 \mathrm{~m})$ and depth of the bassin port $(70 \mathrm{~cm})$ resulted in inbibition of activity in the PPI Cituis especially landing boat and the unloading of the catch.
\end{abstract}

Keywords : port facilities, fishing port, PPI Cituis

\begin{abstract}
ABSTRAK
Fasilitas berperan menunjang kelancaran aktivitas pelabuhan perikanan. Ketidakcukupan kapasitas atau ketidaktersediaan salah satu fasilitas yang diperlukan akan dapat menghambat kelancaran aktivitas pelabuhan tersebut. Permasalahan ini sering ditemukan pada banyak pelabuhan perikanan. PPI Cituis merupakan salah satu dari 7 PPI di Kabupaten Tangerang yang dapat memberikan kontribusi Pendapatan Asli Daerah tertinggi. Tujuan penelitian ini mengetahui kondisi dan kapasitas fasilitas tersedia terkait dengan kelancaran aktivitas di PPI Cituis. Metode penelitian adalah kasus terhadap aktivitas dan fasilitas PPI Cituis. Analisis dilakukan secara deskriptif setelah dilakukan identifikasi terhadap fasilitas dan aktivitas yang ada dan penghitungan kembali kapasitas tempat pelelangan ikan, dermaga dan kolam pelabuhan. Hasil penelitian menunjukkan bahwa berdasarkan tiga belas jenis aktivitas kepelabuhanan perikanan yang tercantum dalam UU RI Nomor 45 Tahun 2009 tentang Perikanan, maka PPI Cituis telah melaksanakannya 9. Permasalahan kurangnya kapasitas dermaga $(154,18 \mathrm{~m})$ dan kedalaman kolam pelabuhan $(70 \mathrm{~cm})$ mengakibatkan terhambatnya aktivitas di PPI Cituis khususnya pendaratan kapal dan pembongkaran hasil tangkapan.
\end{abstract}

Kata kunci: fasilitas pelabuhan, pelabuhan perikanan, PPI Cituis

\section{PENDAHULUAN}

\section{1. Latar Belakang}

Pangkalan Pendaratan Ikan sebagai pusat pengembangan ekonomi perikanan memiliki peranan yang sangat penting dalam memanfaatkan sumberdaya perikanan. Peranan penting pangkalan pendaratan ikan adalah menampung dan memasarkan hasil tangkapan dari kapalkapal penangkapnya yang umumnya berukuran 5-10 GT.

Fasilitas sangat berperan dalam menunjang aktivitas di pelabuhan perikanan. Ketidakcukupan kapasitasnya, ketidaktersediaan salah satu fasilitas yang diperlukan dan tata letaknya yang tidak mendukung akan dapat menghambat kelancaran berbagai aktivitas di pelabuhan. Fasilitas diperlukan mulai saat persiapan kegiatan operasi penangkapan ikan sampai saat hasil tangkapan didaratkan dan dipasarkan. Belum lengkapnya fasilitas yang memadai akan mempengaruhi pelaksanaan fungsi-fungsi pelabuhan perikanan. Lubis (2006) mengemukakan bahwa terlaksana atau tidaknya fungsifungsi kepelabuhanan perikanan secara optimal adalah merupakan indikasi keberhasilan atau tidaknya pengelolaan suatu pelabuhan perikanan. Selanjutnya

\footnotetext{
${ }^{1}$ Corresponding author

${ }^{2}$ Staf Departemen Pemanfaatan Sumberdaya Perikanan, FPIK - IPB
} 
dikatakan bahwa jenis dan kapasitas fasilitas akan berkembang sesuai dengan kebutuhan operasional pelabuhan atau dengan kata lain bahwa berkembangnya produksi hasil tangkapan yang didaratkan hendaknya dapat diimbangi dengan pengembangan jenis dan kapasitas fasilitasnya.

Pemerintah Kabupaten Tangerang memiliki misi untuk mengubah daerahnya dari yang 80\% masyarakatnya hidup dari sektor pertanian menjadi kawasan industri berbasiskan sektor perikanan dan kelautan. Dengan demikian perlu penyediaan fasilitas pelabuhan untuk mendorong perkembangan industri ini (Kompas, 2008).

Pangkalan Pendaratan Ikan (PPI) Cituis merupakan salah satu PPI yang terletak di Kabupaten Tangerang. PPI Cituis memiliki prospek pengembangan yang lebih baik diantara ketujuh PPI yang terdapat di Kabupaten Tangerang. $\mathrm{Hal}$ ini diindikasikan dari ramainya transaksi pelelangan ikan di Tempat Pelelangan Ikan (TPI) setiap harinya dan memiliki kontribusi PAD (Pendapatan Asli Daerah) tertinggi dari retribusi pelelangan ikan. Sebagai TPI yang lebih baik dari TPI lainnya di Kabupaten Tangerang, Cituis dikenakan target kenaikan retribusi setiap tahunnya oleh Dinas Perikanan dan Kelautan Kabupaten Tangerang. Retribusi lelang dari TPI Cituis yang ditargetkan sebesar Rp 120.000.000,00 pada tahun 2008 realisasinya adalah Rp 120.500.000,00. (TPI Cituis, 2009).

Seiring berkembangnya perikanan di Kabupeten Tangerang, berbagai permasalahan telah terjadi, diantaranya kapasitas fasilitas pelabuhan perikanan yang tidak mencukupi lagi. Hal ini terlihat dari terganggunya aktivitas bongkar muat karena dermaga yang kurang panjang, sulitnya kapal berlabuh karena kolam pelabuhan yang dangkal.

Keterbatasan kapasitas fasilitasfasilitas tersebut akan berpengaruh terhadap kelancaran aktivitas kepelabuhanan sehingga fungsi pelabuhan tidak tercapai secara optimal dan pada akhirnya akan berpengaruh terhadap perkembangan perikanan tangkapnya. Sehubungan dengan hal tersebut, kiranya penting dilakukan penelitian untuk mengetahui ketersediaan fasilitas dan kapasitasnya terkait dengan perkembangan produksi perikanan dan perannya terhadap kelancaran aktivitas di PPI Cituis.

\section{METODOLOGI PENELITIAN}

Penelitian dilakukan pada bulan Agustus 2009 di Pangkalan Pendaratan Ikan (PPI) Cituis Tangerang. Metode yang digunakan adalah studi kasus tentang peranan fasilitas terhadap kelancaran aktivitas PPI Cituis. Fasilitas yang diteliti antara lain tempat pelelangan ikan (TPI), dermaga dan kolam PPI.

Pengumpulan data dilakukan melalui pengamatan langsung dan pengisian kuesioner serta wawancara terhadap responden untuk mengetahui kondisi fisik, kapasitas dan ukuran fasilitas pokok (dermaga, kolam pelabuhan) dan fasilitas fungsional (gedung TPI). Penentuan jumlah responden dilakukan secara purposive sampling kepada pihak pengelola PPI (2 orang) untuk mengetahui fasilitas yang tersedia (jenis, ukuran dan kapasitasnya); produksi hasil tangkapan yang didaratkan; nelayan (15 orang) untuk mengetahui jenis dan ukuran armada penangkapan serta kapasitas palkanya; besarnya produksi hasil tangkapan per trip penangkapan dan sistem penjualannya, rata-rata jumlah kapal bongkar ikan per hari; fishing trip menurut jenis kapal dan alat tangkap serta permasalahan terhadap PPI terkait dengan fasilitasnya; pedagang (6 orang) untuk mengetahui sistem pembelian ikan, volume pembelian ikan, harga ikan per $\mathrm{kg}$ untuk tiap jenisnya, bahan dan alat yang digunakan untuk menjaga mutu hasil tangkapan, fasilitas yang dimiliki untuk menyimpan sementara hasil tangkapan dan permasalahan terhadap fasilitas tempat pelelangan ikan. Penelitian ini juga ditunjang dengan data sekunder dari beberapa instansi terkait yaitu Pengelola PPI Cituis; Dinas Perikanan dan Kelautan Kabupaten Tangerang; dan Badan Pusat Statistik Provinsi Banten.

1) Analisis aktivitas di PPI Cituis

Analisis aktivitas ini dilakukan secara deskriptif setelah dilakukan pengamatan terhadap kelancaran aktivitas kepelabuhanan khususnya aktivitas pembongkaran dan pemasaran ikan sedangkan analisis fasilitas 
dilakukan secara deskriptif setelah dilakukan identifikasi terhadap keberadaan, kondisi dan kapasitas fasilitas PPI Cituis.

2) Analisis kapasitas fasilitas terkait kelancaran aktivitas di PPI Cituis.

Analisis kapasitas fasilitas dibatasi pada dermaga, kolam pelabuhan dan tempat pelelangan ikan. Berdasarkan hasil pengamatan, fasilitas-fasilitas tersebut rutinitas dipakai oleh nelayan PPI Cituis dan keberadaannya sangat berperan penting dalam menunjang kelancaran aktivitasnya. Kapasitas terpasang merupakan kapasitas maksimal yang dapat ditampung. Kapasitas fasilitas yang seharusnya adalah kapasitas fasilitas terpasang yang disesuaikan dengan kebutuhan pengembangannya.

Analisis data dilakukan dengan perhitungan kapasitas sebagai berikut:

\section{(1) Dermaga}

Panjang dermaga yang dibutuhkan dapat dicari dengan rumus: (Anonimous, 1984)

$L=\frac{(l+s) \times n \times a \times h}{u \times d}$

Keterangan:

$L$ : Panjang dermaga $(\mathrm{m})$

$l$ : Panjang kapal (m)

$s$ : Jarak antar kapal $(\mathrm{m})$

$n$ : Jumlah kapal yang memakai dermaga (unit/hari)

$a$ : Berat kapal (ton)

$h$ : Lama kapal di dermaga (jam)

$u$ : Produksi per hari (ton)

$d$ : Lama fishing trip (jam)

(2) Kolam PPI

a) Kedalaman kolam PPI

Kedalaman perairan di wilayah kolam pelabuhan pada saat muka air terendah (LLWS) dapat ditentukan dengan rumus: (Anonimous, 1984)

$D=d+1 / 2 H+S+C$

Keterangan:

$D$ : Kedalaman perairan $(\mathrm{cm})$

$d$ : Draft kapal terbesar $(\mathrm{cm})$
$H$ : Tinggi gelombang maksimum $(\mathrm{H}$ maks $=50 \mathrm{~cm}$ )

$S$ : Tinggi ayunan kapal yang melaju $(10-30 \mathrm{~cm})$

$C$ : Jarak aman dari lunas kapal ke dasar perairan $(25-100 \mathrm{~cm})$

b) Luas kolam pelabuhan

Luas kolam pelabuhan dapat dihitung dengan rumus berikut: (Anonimous, 1984)

$L=L t+(3 \times n \times l \times b)$

$L t=\pi \times l^{2}$

п: 3,14

Keterangan :

$L \quad$ : Luas kolam pelabuhan $\left(\mathrm{m}^{2}\right)$

Lt : Luas untuk memutar kapal $\left(\mathrm{m}^{2}\right)$

$n \quad$ : Jumlah kapal maksimum yang

berlabuh

$l \quad$ : Panjang kapal terbesar (m)

$b \quad:$ Lebar kapal (m)

Lt : Luas untuk memutar kapal, radius pemutarannya minimum satu kali panjang kapal terbesar $\left(\mathrm{m}^{2}\right)$.

(3) Tempat Pelelangan Ikan

Analisis ini diperoleh dari perhitungan luas ruang pelelangan sebagai berikut: (T. Yano dan M. Noda, 1970 vide Anonimous, 1981)

$S=\frac{N \times P}{R \times \alpha}$

Keterangan:

$S$ : Luas ruang pelelangan $\left(\mathrm{m}^{2}\right)$

$N \quad$ : Jumlah produksi per hari (ton)

$P \quad$ : Daya tampung produksi $\left(\mathrm{m}^{2} /\right.$ ton)

$R \quad$ : Intensitas lelang per hari (kali)

a : Perbandingan ruang lelang dengan gedung lelang $(0,217-0,394)$

Setelah dilakukan perhitungan terhadap fasilitas-fasilitas di atas maka bisa disimpulkan apakah peran fasilitas yang ada saat ini masih mendukung perkembangan produksi perikanan dan kelancaran aktivitas di PPI Cituis dan berapakah kapasitas seharusnya untuk dermaga, kolam PPI dan TPI-nya saat ini. 


\section{HASIL DAN PEMBAHASAN}

\subsection{Aktivitas dan Fasilitas PPI Cituis}

Berdasarkan Undang-Undang Republik Indonesia Nomor 45 Tahun 2009 tentang Perubahan atas UndangUndang Nomor 31 Tahun 2004 tentang Perikanan pada pasal 41 A ayat 2 , bahwa PPI Cituis telah melaksanakan pengelolaan sebagian besar aktivitas antara lain pelayanan administrasi tambat dan labuh kapal perikanan; pelayanan bongkar hasil tangkapan, muat bahan perbekalan; pelaksanaan pembinaan mutu dan pengolahan hasil perikanan; pemasaran dan distribusi ikan; pengumpulan data hasil tangkapan; pelaksanaan penyuluhan dan pengembangan masyarakat nelayan; pelaksanaan kegiatan operasional kapal perikanan; pelaksanaan kesyahbandaran dan pengendalian lingkungan (kebersihan, keamanan dan ketertiban, kebakaran dan pencemaran). Namun demikian pengelolaan fasilitas maupun aktivitasnya terlihat belum optimal, antara lain karena masih bergabungnya dermaga untuk bertambatnya kapal perikanan dan kapal transportasi sehingga fasilitas dermaga yang ada menjadi tidak mencukupi. Dermaga yang dikelola oleh Dinas Perhubungan Kota Tangerang ini sebenarnya adalah dermaga transportasi untuk membawa penumpang ke Pulau Tidung, Pulau Panggang, Pulau Pari, Pulau Pancang atau Pulau Payung. Namun dalam pengoperasi-annya terdapat juga kapal perikanan yang bersandar walaupun jumlahnya sedikit yaitu hanya sekitar 8 unit/hari, selebihnya (90,5 \%) melakukan pembongkaran ikan di tepitepi kolam pelabuhan yang dekat dengan TPI (Tempat Pelelangan Ikan). Dermaga yang ada saat ini letaknya jauh dari TPI. TPI juga belum dioptimalkan untuk memasarkan ikan melalui proses pelelangan seperti yang seharusnya fungsi awal TPI atau hanya $45 \%$ ikan yang dilelang. Fasilitas SPDN (Solar Packed Dealer Nelayan) yang ada belum memenuhi seluruh kebutuhan konsumen, saat ini hanya dapat menyediakan 96.000 liter/bulan atau hanya $23,90 \%$ dari total kebutuhan nelayan sedangkan $76,10 \%$ atau 305.692,1 liter diperoleh dari tempat lain atau bakul. Permasalahan selanjutnya adalah kebersihan lingkungannya masih kurang, hal ini diindikasikan masih kotornya lantai TPI dan perairan kolam. Menurut Smith et al, bahwa pihak pelabuhan seharusnya bertanggung jawab terhadap pengelolaannya karena keberadannya di wilayah pesisir terutama apabila pesisir tersebut juga terdapat aktivitas wisata bahari. Pemantauan wilayah pesisir dan wisata bahari ini memang merupakan salah satu fungsi pelabuhan perikanan yang belum dilaksanakan di PPI Cituis selain juga fungsi pengawasan dan pengendalian sumberdaya perikanan dan fungsi karantina ikan.

\subsection{Kapasitas Fasilitas Terkait Kelan- caran Aktivitas di PPI Cituis}

Melihat semakin banyaknya jumlah kapal yang beraktivitas, maka PPI Cituis dapat dikatakan cukup ramai, sehingga perlu penghitungan kembali kapasitasnya untuk menjamin kelancaran aktivitas di PPI Cituis. Fasilitas yang kapasitasnya dihitung kembali, diantaranya :

\section{1) Dermaga}

Dermaga di PPI Cituis terbuat dari kayu dengan panjang 25,82 $\mathrm{m}$ dan lebar 7,96 m. Dermaga tersebut terutama digunakan untuk bersandarnya kapal transportasi sedangkan kapal perikanan yang merapatkan kapalnya di dermaga rata-rata hanya 8 unit setiap hari. Seperti telah dijelaskan sebelumnya bahwa dermaga yang ada saat ini sebenarnya dermaga transportasi untuk membawa penumpang ke pulau-pulau kecil di sekitarnya. Namun seiring dengan semakin besarnya ukuran kapal perikanan yang datang ke PPI Cituis maka kapal-kapal tersebut memerlukan dermaga untuk bersandar, sementara kapal-kapal yang berukuran kecil lebih senang mendaratkan ikan dan muat bahan perbekalan di tepi kolam pelabuhan yang lebih dangkal. Waktu yang dibutuhkan untuk membongkar hasil tangkapan di dermaga bervariasi. Rata-rata nelayan gardan membongkar hasil tangkapannya selama 6-7 jam untuk rata-rata $1.300 \mathrm{~kg}$ dan untuk nelayan rampus dan pancing ulur selama 1-2 jam untuk rata-rata $700 \mathrm{~kg}$. Namun rata-rata waktu proses bongkar menjadi 3 jam karena termasuk didalamnya waktu antrian mengingat masih terbatasnya kolam pelabuhan baik 
kedalaman maupun luasnya. Kapalkapal tersebut memerlukan waktu yang lebih lama untuk mencapai dermaga karena banyaknya kapal yang berlabuh (bercampur dengan kapal transportasi). Kapal-kapal yang berlabuh di PPI Cituis terdiri dari perahu motor tempel dan kapal motor. Ukuran kapal motor berkisar antara 1-20 GT. Panjang kapal antara 5-17 m. Jarak antar kapal di kolam pelabuhan adalah $25 \mathrm{~cm}$. Lama fishing trip kapal perikanan yang berfishing base di PPI Cituis bervariasi antara 12 sampai 71 jam. Produksi hasil tangkapan ikan di PPI Cituis setiap harinya adalah 3,31 ton.

Panjang dermaga yang tersedia saat ini masih belum memenuhi standar panjang yang dibutuhkan oleh sejumlah kapal yang bertambat di PPI Cituis. Merujuk pada kriteria teknis klasifikasi pelabuhan perikanan menurut DKP (2006) bahwa panjang dermaga bongkar pelabuhan perikanan tipe D sekurangkurangnya adalah $50 \mathrm{~m}$. Hal tersebut diartikan bahwa, panjang dermaga PPI Cituis saat ini masih belum memenuhi standar kriteria. Berdasarkan perhitungan, perlu adanya penambahan panjang dermaga $154,18 \mathrm{~m}$ atau panjang dermaga menjadi $180 \mathrm{~m}$ untuk mengakomodasi kebutuhan merapatnya kapal-kapal penangkap ikan yang selama ini merapat di tepi-tepi kolam pelabuhan dekat TPI. Menurut Kramadibrata (2002), perancangan dermaga didasarkan pada perkiraan jumlah dan ukuran kapal yang akan bertambat agar kapal-kapal dapat dengan mudah dan aman melakukan bongkar muat. Namun penambahan tersebut dilakukan apabila kapal angkutan penumpang tetap pada dermaga yang sama, dan perlu dilakukan pemisahan antara dermaga untuk kapal perikanan dengan kapal penumpang agar proses bongkar muat kapal perikanan berjalan dengan lancar. Sebaliknya apabila dermaga kapal penangkapan terpisah maka dermaga yang ada tetap untuk dermaga kapal angkutan dan perlu pembangunan dermaga khusus untuk kapal penangkapan ikan. Dermaga yang ada di PPI juga tidak dilengkapi dengan fender untuk melindungi kapal dari kerusakan akibat benturan dengan dermaga saat bertambat. Menurut Bambang dan Suherman, 2005, dermaga seharusnya disediakan fender walaupun sederhana yang terbuat dari batang kelapa dan ban bekas yang bersifat sementara.

Pada kondisi saat ini, terlihat bahwa pemanfaatan dermaga bongkar telah melebihi kapasitas yang ada. Tingkat pemanfaatan dermaga bongkar ini setiap tahun meningkat karena bertambahnya jumlah kapal yang melakukan bongkar. Hal lain yang berpengaruh pada peningkatan pemanfaatan dermaga adalah bertambahnya waktu bongkar (rata-rata setiap kapal memerlukan waktu bongkar 3 jam). Di PPI Cituis tidak ada ketentuan pelaksanaan pembongkaran hasil tangkapan harus mendahulukan hasil tangkapan tertentu. Sistem pendaratan ikan di PPI Cituis adalah dengan metode antrian dimana kapal yang datang pertama dapat melakukan proses pendaratan ikan. Lain halnya Pelabuhan Perikanan Samudera Cilacap dimana pelaksanaan bongkar dilakukan bergantian. Kapal dengan hasil tangkapan utama udang mendapat giliran lebih dahulu karena pembongkarannya relatif singkat dan udang dilelang terlebih dahulu. Setelah itu barulah kapal-kapal yang memiliki hasil tangkapan berupa ikan untuk dibongkar (Bambang dan Suherman, 2005).

\section{2) Kolam PPI \\ Kedalaman kolam PPI}

Kolam pelabuhan merupakan bagian dari sungai yang memiliki luas $25.000 \mathrm{~m}^{2}$ dengan rincian ukuran panjang $1000 \mathrm{~m}$ dan lebar $25 \mathrm{~m}$. Kedalaman kolam PPI Cituis hanya 1,25 $\mathrm{m}$ dan sering terjadi pendangkalan sehingga kapal-kapal berukuran 5-20 GT sulit bertambat dan berlabuh di kolam pelabuhan. Kapal-kapal tersebut dapat memasuki areal kolam pelabuhan setelah air pasang dengan cara didorong oleh tenaga manusia dan menggunakan bambu yang disentuhkan pada dasar perairan, kemudian diletakkan di belakang kapal lalu didorong ke arah depan dengan posisi kapal ke arah depan (Gambar 1). Kapal tersebut didorong mulai jarak 50 meter dari muara sungai. Kondisi ini tentunya akan memperlambat proses pendaratan kapal yang akan membongkar hasil tangkapannya. Ukuran kapal yang bertambat dan berlabuh di kolam pelabuhan terdiri atas perahu motor tempel dan kapal motor. 
Tinggi gelombang maksimum di kolam pelabuhan adalah $20 \mathrm{~cm}$ dan tinggi ayunan kapal yang melaju adalah $10 \mathrm{~cm}$. Tingginya air di kolam pelabuhan mempengaruhi draft kapal dan jarak aman lunas kapal ke dasar perairan. Draft kapal terbesar di PPI Cituis adalah $150 \mathrm{~cm}$ dan jarak aman dari lunas kapal ke dasar perairan adalah $25 \mathrm{~cm}$. Kondisi Muara Kali Cituis yang berada di perkampungan nelayan, kembali dangkal walaupun pernah dilakukan pengerukan yang menghabiskan dana sekitar Rp 1,7 miliar.

Berdasarkan luas dan kedalamannya, kolam pelabuhan di PPI Cituis saat ini belum memenuhi standar yang seharusnya. Kedalaman kolam pelabuhan $(-125 \mathrm{~cm})$ masih terlalu dangkal, menurut hasil perhitungan kedalamannya minimal perlu ditambah $70 \mathrm{~cm}$ sehingga kedalaman kolam menjadi $195 \mathrm{~cm}$. Hal ini dilakukan agar kapal-kapal besar (5-20 GT) tidak kesulitan untuk berlabuh. Kedalaman kolam PPI Cituis belum memenuhi kriteria teknis klasifikasi pelabuhan perikanan menurut DKP (2006) bahwa kedalaman kolam pelabuhan tipe D sekurang-kurangnya adalah $2 \mathrm{~m}$. Pihak KUD Mina Samudera akan melakukan pengerukan kolam dengan kapal keruk. Hal ini sesuai dengan Kramadibrata, 2002 bahwa pengerukan diperlukan untuk memelihara kedalaman suatu kolam/alur pelayaran atau alur sungai (maintenance dredging), dikarenakan adanya proses pergerakan dan pengendapan lumpur (sedimen transport).

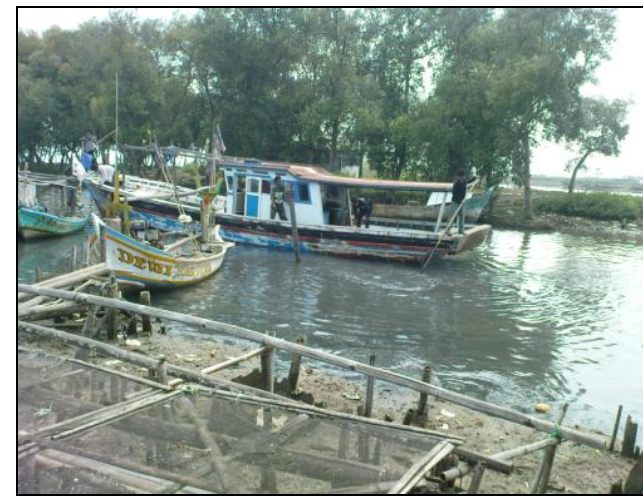

Gambar 1. Cara kapal memasuki kolam pelabuhan ketika air surut

Pada umumnya kedalaman dasar kolam pelabuhan ditetapkan berdasarkan sarat maksimum ( $\max$ draft) kapal yang bertambat ditambah dengan jarak aman (clearance) sebesar $(0,8-1,0) \mathrm{m}$ di bawah lunas kapal. Jarak aman ini ditentukan berdasarkan ketentuan operasional pelabuhan (penambatan kapal dengan/tanpa kapal tunda) dan konstruksi dermaga (Kramadibrata, 2002). Namun kenyataan di PPI Cituis, jarak aman dari bawah lunas kapal hingga ke dasar kolam hanya $25 \mathrm{~cm}$ sehingga belum memenuhi kriteria jarak standar aman.

\section{Luas kolam pelabuhan}

Kolam pelabuhan di PPI Cituis merupakan bagian dari sungai yang memiliki luas $25.000 \mathrm{~m}^{2}$ dengan rincian ukuran panjang $1000 \mathrm{~m}$ dan lebar $25 \mathrm{~m}$. Dengan luasan tersebut, kapal-kapal yang berada di PPI Cituis saat ini kesulitan untuk memutar (turning basin), mendaratkan hasil tangkapannya dan keluar untuk melaut. Selain itu terjadi antrian kegiatan bongkar sehingga ruang gerak kapal yang akan berlayar menjadi terbatas. Ukuran panjang dan lebar kapal terbesar di PPI Cituis adalah $17 \mathrm{~m}$ dan $4 \mathrm{~m}$. Menurut kriteria teknis klasifikasi pelabuhan perikanan menurut DKP (2006) bahwa kapasitas tampung kolam pelabuhan tipe D (tipe PPI) sekaligus adalah 20 unit kapal. Berdasarkan banyaknya kapal penangkap ikan yang berlabuh untuk membongkar hasil tangkapannya dan muat bahan perbekalan per hari di dermaga dan di tepi-tepi kolam (84 unit) maka menurut hasil perhitungan kolam pelabuhan perlu luasan $18.043 \mathrm{~m}^{2}$. Apabila dibandingkan dengan luasan kolam yang ada, maka seharusnya seluruh kapal penangkapan masih bisa ditampung. Permasalahan antrian yang terjadi adalah karena terjadinya pendangkalan dan adanya kapal 
angkutan penumpang antar pulau yang sama-sama menggunakan kolam pelabuhan tersebut. Pada saat air surut, nelayan tidak bisa melalui sungai ini khawatir lunas kapal akan mengenai lumpur dan membuat kipas mesin kapal menjadi rusak sehingga nelayan harus menarik kapalnya bahkan harus berlabuh di muara. Dengan demikian agar pengoperasian PPI Cituis dapat lebih optimal maka perlu kiranya Pemerintah Daerah mencarikan alternatif lokasi PPI Cituis sebagai pendaratan kapal penangkap ikan mengingat awal fungsi pembangunan dermaga adalah untuk kapal angkut penumpang antar pulaupulau kecil di sekitarnya. Posisi tambatan kapal adalah dengan posisi miring. Hal tersebut merupakan posisi terbaik mengingat kolam pelabuhan yang merupakan sungai tersebut lebarnya tidak cukup luas untuk posisi kapal tegak ketika bersandar.

\section{3) Tempat Pelelangan Ikan (TPI)}

Berdasarkan hasil pengamatan, tempat pelelangan ikan (ruang lelang) yang dikelola oleh KUD Mina Samudera ini sejak tahun 2000 masih cukup untuk menampung hasil tangkapan yang didaratkan di PPI Cituis. Namun nelayan masih kurang memanfaatkannya.

Gedung TPI PPI Cituis memiliki luas bangunan 290,62 $\mathrm{m}^{2}$. Di dalam gedung TPI terdapat kantor, ruang peralatan, tempat kasir, ruang juru tulis, mushola, toilet dan ruang lelang. Luas ruang lelang adalah 206,64 $\mathrm{m}^{2}$ dan jumlah luas ruang kantor, ruang peralatan, tempat kasir, ruang juru tulis, mushola dan toilet adalah sebesar 83,98 $\mathrm{m}^{2}$. Ruang lelang dipakai untuk menimbang, memperagakan dan melelang ikan (Lubis, 2006). Perbandingan antara ruang lelang dengan gedung lelang (a) di PPI Cituis adalah 71:100. Nilai alpha tersebut keluar range yang telah ditentukan dari rumus karena berdasarkan hasil pengamatan ruang lelang di PPI Cituis lebih luas dari ruang kantor dan lainlain. Gedung TPI di luar negeri misalnya Prancis terdiri atas ruang lelang, kantor administrasi, pengepakan dan penangan- an yang masing-masing juga membutuhkan ruang yang luas sehingga ruang lelang luasnya lebih kecil dari total ruang-ruang lainnya.

Sejak dibangun, gedung TPI Cituis memiliki daya tampung produksi hasil tangkapan sebesar 1 ton/10 $\mathrm{m}^{2}$. Dalam satu hari, kegiatan pelelangan ikan dilaksanakan sebanyak tiga kali. Jumlah produksi ikan di PPI Cituis adalah 3,31 ton per hari. Jumlah tersebut meliputi ikan yang dilelang dan yang tidak dilelang. Proporsi ikan yang dilelang adalah $45 \%$ atau sekitar 1,49 ton per hari dan ikan yang tidak dilelang adalah $55 \%$ yaitu sekitar 1,82 ton per harinya. Peran fasilitas TPI masih kurang karena masih banyak nelayan yang belum meman-faatkannya. Dalam proses pengembangannya, gedung TPI akan dipindahkan ke dekat pantai agar proses pengangkutan hasil tangkapan lebih mudah karena jaraknya lebih dekat dengan dermaga. Saat ini gedung TPI berada $300 \mathrm{~m}$ dari tepi pantai dan $150 \mathrm{~m}$ dari dermaga sehingga memerlukan pengangkutan.

Berdasarkan perhitungan, luas gedung TPI seharusnya minimal sebesar $99,52 \mathrm{~m}^{2}$ dan luas ruang lelang minimal sebesar $15,54 \mathrm{~m}^{2}$. Luas ruang lelang berdasarkan standar kriteria produksi dan fasilitas pelabuhan perikanan untuk pelabuhan tipe D adalah $150 \mathrm{~m}^{2}$ (Dinas Kelautan dan Perikanan Kabupaten Subang, 2004c vide Indrianto, 2006). Berdasarkan antara kebutuhan dan kapasitas maka dapat disimpulkan bahwa luas gedung TPI sangat mencukupi dan tidak perlu penambahan luas, bahkan masih mencukupi untuk mengantisipasi pengembangan produksi hasil tangkapan. Sebaliknya pihak pelabuhan perlu memaksimalkan pemanfaatan ruang lelang karena sampai saat ini ruang lelang yang tersedia tidak semuanya digunakan untuk melelang ikan.

Berdasarkan pengamatan dan perhitungan terhadap sebagian fasilitas di PPI Cituis dapat disajikan ukuran fasilitas yang tersedia dan ukuran yang seharusnya (Tabel 2). 
Tabel 2. Hasil perhitungan ukuran beberapa fasilitas di PPI Cituis, 2010

\begin{tabular}{|c|l|c|c|}
\hline \multirow{2}{*}{ No. } & \multicolumn{1}{|c|}{ Fasilitas } & \multicolumn{2}{|c|}{ Ukuran } \\
\cline { 3 - 4 } & & Tersedia & Seharusnya \\
\hline 1 & Luas ruang pelelangan & $206,64 \mathrm{~m}^{2}$ & $15,54 \mathrm{~m}^{2}$ \\
\hline 2 & Panjang demaga & $25,82 \mathrm{~m}$ & $180 \mathrm{~m}$ \\
\hline 3 & Kedalaman kolam pelabuhan & $125 \mathrm{~cm}$ & $195 \mathrm{~cm}$ \\
\hline 4 & Luas kolam pelabuhan & $25.000 \mathrm{~m}^{2}$ & $72.307,46 \mathrm{~m}^{2}$ \\
\hline
\end{tabular}

Hasil perhitungan menunjukkan bahwa perlunya penambahan kapasitas terhadap dua fasilitas yaitu dermaga dan kolam pelabuhan. Hal tersebut juga didukung oleh pihak pelabuhan yang menyatakan bahwa dengan semakin banyaknya kapal yang berlabuh dan bertambat dan semakin besarnya ukuran kapal penangkap ikan di PPI Cituis serta semakin jauhnya daerah operasi penangkapan, maka PPI Cituis memiliki potensi untuk dikembangkan menjadi pelabuhan perikanan tipe B. Namun demikian untuk mengantisipasi pengembangan jumlah kapal maupun ukurannya maka luas kolam pelabuhan yang ada tidak memungkinkan atau dengan kata lain tidak dapat ditambah luasnya karena kolam yang ada merupakan bagian dari sungai sehingga perlu alternatif lokasi lain, untuk sementara waktu kiranya cukup dilakukan pengaturan dengan memisahkan dermaga untuk kapal penangkap ikan dan kapal transportasi. Hal ini dapat dilakukan dengan membangun dermaga sepanjang $180 \mathrm{~m}$ dan menambah dalamnya kolam yang saat ini menjadi tempat berlabuh kapalkapal ukuran kecil .

Hasil penelitian ini terlihat jelas bahwa peran fasilitas tentunya semakin penting dalam mendukung kelancaran aktivitas PPI Cituis. Terbatasnya panjang dermaga, menyatunya kolam pelabuhan bagi kapal-kapal transportasi dan kapalkapal perikanan dan adanya pendangkalan di kolam pelabuhan, menjadikan hambatan bagi aktivitas pendaratan kapal dan proses pembongkaran hasil tangkapannya. Akibat hambatan dari aktivitas pendaratan ikan, menjadikan aktivitas pemasaran ikan juga terhambat dan tidak optimal antara lain pemasaran ikan di TPI tidak dapat dilakukan tepat sesuai jadwal yang diberikan, khususnya apabila dilakukan pelelangan ikan yang menghendaki kepastian waktu jual bagi pedagang. Apabila pelelangan ikan dapat dilakukan maka nelayan dan pedagang akan mendapatkan harga jual yang layak. Menurut Yusuf, 2005 bahwa pelaksanaan pelelangan ikan akan meningkatkan penyerapan tenaga kerja dan pendapatan nelayan karena harga yang terbentuk lebih baik. Pengoptimalan aktivitas pelelangan ikan tentunya akan mengoptimalkan juga pemanfaatan TPI yang ada.

\section{KESIMPULAN}

1) PPI Cituis telah melaksanakan pengelolaan aktivitas kepelabuhanan perikanan walaupun belum semua fungsi pelabuhan perikanan menurut Undang-Undang Republik Indonesia Nomor 45 Tahun 2009 tentang Perikanan tersebut terlaksana. Aktivitas pendaratan ikan dan pemasaran hasil tangkapan di TPI, perlu lebih dioptimalkan lagi.

2) Terdapat beberapa fasilitas yang sebenarnya telah mempengaruhi kelancaran aktivitas diantaranya dermaga dan kolam pelabuhan. Penambahan kapasitas fasilitas dermaga dan kedalaman kolam pelabuhan tentunya akan dapat melancarkan aktivitas di PPI Cituis yaitu penambahan panjang dermaga $154,18 \mathrm{~m}$, dan pengerukan kolam pelabuhan sedalam $70 \mathrm{~cm}$. Perlu pengaturan kembali lokasi kolam pelabuhan bagi kapal-kapal transportasi dan kapal-kapal perikanan. 


\section{DAFTAR PUSTAKA}

Azhar, S. L. F. dan Abdussamad. 2002. Analisis Sektor Basis dan Non Basis di Provinsi Nanggroe Aceh Darussalam.

http://ejournal.unud.ac.id/abstrak (7). [15 Juni 2010].

Bambang dan Suherman. 2005. Tingkat Pemanfaatan Fasilitas

Kepelabuhanan di Pelabuhan Perikanan Samudera Cilacap (PPSC). Buletin PSP. No. XIV: 2.

Choppin I. 1993. Infofish International. Kualalumpur: FAO.

[DKP] Departemen Kelautan dan Perikanan. 2006. Keputusan Menteri Kelautan dan Perikanan Nomor: KEP.16/MEN/2006 tentang Pelabuhan Perikanan. Jakarta: DKP.

Anonimous. 1981. Standar Rencana Induk dan Pokok-Pokok Desain untuk Pelabuhan Perikanan dan Pangkalan Pendaratan Ikan. Jakarta: Direktorat Jenderal Perikanan.

Anonimous. $\quad$ 1984. Pokok-Pokok Kebijaksanaan Penyediaan Prasarana Perikanan dalam Menunjang Perikanan (Khusus dalam Kaitan dengan Masalah Pengembangan PPI). Jakarta: Direktorat Jenderal Perikanan.

Indrianto J. 2006. Pengelolaan Aktivitas dan Pengembangan Pelabuhan Perikanan Pantai Muara Ciasem, Kabupaten Subang Ditinjau dari Aspek Fasilitas dan Kualitas Pemasaran Hasil Tangkapan [Skripsi]. Bogor: Fakultas Perikanan dan Ilmu Kelautan, Institut Pertanian Bogor.

Kompas. 2008. Tangerang Utara Jadi Kawasan Industri Perikanan. http: / /www.kompas.

$\mathrm{com} / \mathrm{read} / \mathrm{xml} / 2008 / 11 / 11 / 18535$ 072/Tangerang.Utara.Jadi.Kawasa n.Industri.Perikanan. [ 10 Juni 2009].
Kramadibrata S. 2002. Perencanaan Pelabuhan. Bandung: Penerbit ITB.

Lubis E. 1999. Pola Pengembangan Pelabuhan Perikanan di Wilayah Perairan Selat Malaka dan Laut Cina Selatan yang Efektif dan Efisien. Hasil Penelitian RUT IV (1996-1999). Jakarta: DRN.

Lubis E. 23 Januari 2000. Pelabuhan Ikan Belum Tersentuh Peradaban Modern. Harian Republika.

Lubis E. 2000. Pengelolaan Aktivitas dan Sistem PP/PPI yang Terletak di Wilayah Perairan Laut Jawa. Makalah pada seminar "Managament of Fishery Activities and Fising Port Systems" kampus FPIK-IPB Darmaga. Bogor: 10 hal.

Lubis E. 2003. Konsep-Konsep Pengembangan Sektor Perikanan dan Kelautan di Indonesia. Bogor: Departemen Pemanfaatan Sumberdaya Perikanan, Fakultas Perikanan dan Ilmu Kelautan, Institut Pertanian Bogor.

Lubis E. 2006. Buku I Pengantar Pelabuhan Perikanan. Bogor: Departemen Pemanfaatan Sumberdaya Perikanan, Fakultas Perikanan dan Ilmu Kelautan, Institut Pertanian Bogor.

Nomura $\mathrm{M}$ and $\mathrm{T}$ Yamazaki. 1977. Fishing Techniques I. Tokyo: Japan International Agency.

Peraturan Presiden. 2006. Peraturan Presiden Republik Indonesia Nomor 19 Tahun 2006 tentang Rencana Kerja Pemerintah Tahun 2007. Jakarta.

Santoso, J. Haluan, K. Mudikdjo dan A. Fauzi. 2008. Reposisi Sektor Kelautan dan Perikanan dalam Perekonomian Nasional. Jurnal Ilmiah Teknologi dan Manajemen Perikanan Tangkap. Bogor. Vol. XVII No. 2: 241-247.

Smith, H.D., J.E. Halliday, A.K.C. Beresford. 1984. La Manche: L'Aménagement des Littoraux et de la Mer. Revue/Jurnal Etudes 
Normandes " Le Havre, Métropole de la mer". Mont-Saint-Aignan. France. No.3 : 57-66.

Sriyanti, N., I. Muflikhati, A. Fatchiya. 2006. Persepsi Nelayan tentang Pendidikan Formal di Kecamatan Rembang, Kabupaten Rembang, Provinsi Jawa Tengah. Buletin Ekonomi Perikanan Vol. VI No. 3 : 40-49.

Sulistiyanti. 2010. Location Quotient (LQ). http://www.scribd.com/doc/25188 658 /Location-Quotient. [3 Juli 2010].
Suryani, N., S. Amanah, Y.I. Kusumastuti. 2004. Analisis Pendidikan Formal anak pada Keluarga Nelayan di Desa Karangjaladri, Kecamatan Parigi, Kabupaten Ciamis, Provinsi Jawa Barat. Buletin Ekonomi Perikanan Vol. V No. 2 : 33-43.

Yusuf, H., K. Moedikdjo, M.S. Saeni dan L.I. Nasution. 2005. Dampak Pembangunan Pelabuhan Perikanan terhadap Penterapan Tenaga Kerja dan Pendapatan Masyarakat. Buletin Ekonomi Perikanan Vol. VI. No. 1 : 57-64. 